\title{
Testing Pollination Syndromes in OENOThera (ONAGRACEAE)
}

\author{
Kyra N. Krakos ${ }^{1 *}$, Matthew W. Austin ${ }^{2}$ \\ ${ }^{1}$ Maryville University in Saint Louis, Dept Biology, 650 Maryville University Drive, Saint Louis, MO 6314l, USA \\ ${ }^{2}$ University of Missouri - Saint Louis, Dept Biology, 1 University Blvd, Saint Louis, MO 63121, USA
}

\begin{abstract}
Pollinators are considered a major selective force in shaping the diversification of angiosperms. It has been hypothesized that convergent evolution of floral form has resulted in "pollination syndromes" - i.e. suites of floral traits that correspond to attraction of particular pollinator functional groups. Across the literature, the pollination syndrome concept has received mixed support. This may be due to studies using different methods to describe floral traits and/or the pollination syndrome concept being supported more often in species highly reliant on pollinators for reproduction. Here, we assess the predictive ability of pollination syndromes in Oenothera, a species rich clade with pollination systems existing on a gradient of specialization, and in which species are either selfcompatible or self-incompatible. We ask the following questions: Do Oenothera species follow the pollination syndrome concept using traditional, categorical floral trait descriptions and/or quantitative floral trait measurements? And, are floral traits more predictive of primary pollinators in species with specialized pollination systems and/or species that are self-incompatible? Mapping floral traits of 54 Oenothera species into morphospace, we do not find support for the pollination syndrome concept using either categorical or quantitative floral trait descriptions. We do not find support for specialization or breeding system influencing the prediction of primary pollinators. However, we find pollination syndromes were more predictive in Oenothera species with moth pollination systems. Collectively, these results suggest that the pollination syndrome concept cannot be generally applied across taxa and that evolutionary history is important to consider when evaluating the relationship between floral form and contemporary pollinators.
\end{abstract}

Keywords: floral evolution, morphospace, mutualism, pollination syndrome, Oenothera, Onagraceae

\section{INTRODUCTION}

The convergent evolution of floral traits among distantly related angiosperm species is a phenomenon pollination ecologists have long sought to explain (Fenster et al. 2004; Schiestl \& Johnson 2013; Stebbins 1970; van der Niet \& Johnson 2012). Since the late I800s, scholars have recognized pollinator-mediated selection as a force driving floral trait convergence and divergence; Darwin proposed that pollinators are the major selective agent for floral trait evolution (Darwin 1862) and myriad botanists have documented suites of floral traits that correspond to particular pollinator groups (e.g. Delpino I874; Knuth I898; Faegri and van der Pij1 1979; Rosas-Guerrero et al. 2014). Over time, this work led to formalization of the pollination syndrome concept (e.g. Faegri \& van der Pij1 1979; Fenster et al. 2004; Ollerton et al. 2009; Rosas-Guerrero et al. 20I4; Vogel 1954), where a pollination syndrome is a suite of floral traits (e.g. color, odor, morphology, reward) that evolved in response to and are associated with a specific pollinator group (i.e. pollination system) (Faegri \& van der Pij1 1979). Since its formalization, the pollination syndrome concept has played a central role in plant-pollinator studies. Pollination syndromes have been used to help explain floral diversification and plantpollinator interactions (e.g. Fenster et al. 2004; Stebbins

Received 6 May 2020, accepted I2 October 2020

*Corresponding author: kkrakos@maryville.edu
1970) and in 1979, Faegri and van der Pijl outlined II pollination syndromes that became standard in pollination biology studies and are hereafter referred to as the traditional pollination syndromes (Faegri \& van der Pij1 1979). However, despite its centrality in pollination research, numerous scholars have questioned the validity of the pollination syndrome concept (e.g. Gong et al. 2015; Ollerton et al. 2009; Waser et al. 1996).

Throughout the literature, the pollination syndrome concept has been critiqued for numerous reasons (e.g. Gong et al. 2015; Ollerton et al. 2009; Waser et al. 1996). First, pollination syndromes are potentially too limited an explanation of the complex relationships between a plant and a visitor. There are multiple reasons a visitor might interact with a plant other than pollination, and these interactions can affect the evolution of floral traits (Ashman \& Majetic 2006; Chittka et al. 1999; Knauer \& Schiestl 2017; Lehtilä \& Strauss I999; Yang \& Guo 2005). Second, inherent to the concept of pollination syndromes is the idea that most plant-pollinator interactions are highly specialized (Fenster 2004; Ollerton et al. 2009; Reynolds et al. 2009); however, plant-pollinator interactions exist on a gradient of specialization, with most plant-pollinator interactions appearing more generalized. Other factors such as the habitat and biogeographical history can impact where higher rates of plant-pollinator specialization are found (Mitchell et al. 2009; Waser \& Ollerton 2006; Waser et al. 1996; Johnson \& Steiner 2000; Fenster et al. 2004). The existence of highly generalized plantpollinator interactions is contrary to the idea that suites of 


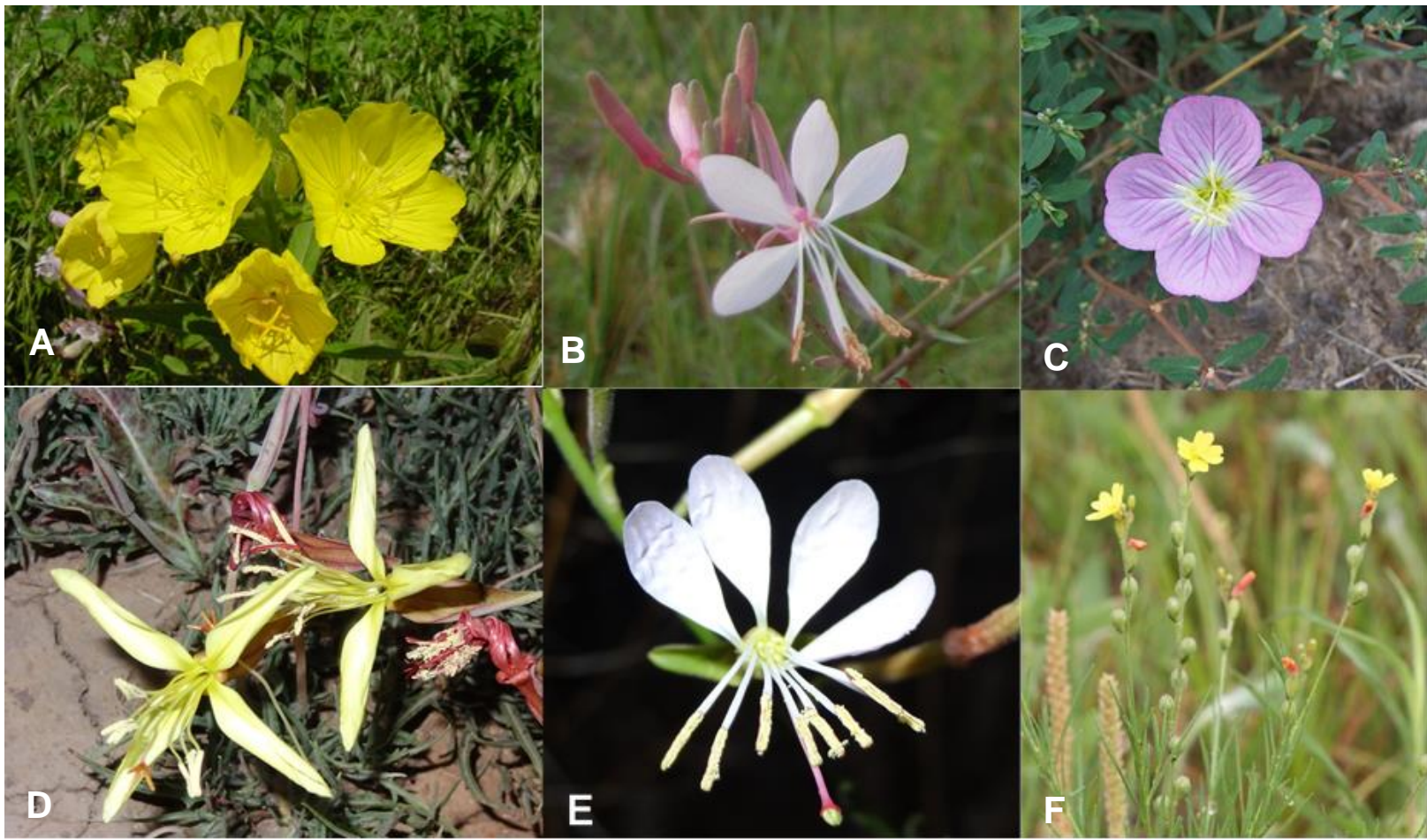

Figure I. A visual overview of the floral trait diversity within Subclade B of Oenothera. A. Oenothera pilosella B. Oenothera dodgeniana C. Oenothera speciosa D. Oenothera havardii E. Oenothera nealleyi F. Oenothera linifolia. Photographs provided by K. N. Krakos.

floral traits attract limited types of pollinators. A final concern is that a discrepancy exists between studies that use categorical floral traits (e.g. the traditional syndromes of Faegri and van der Pij1 1979) and those that use quantitative floral traits (Smith 2010; Smith et al. 2008; Tripp \& Manos 2008; Whittall \& Hodges 2007) as a tool to infer a plant's pollinator. While quantitative measurements are more objective than categorical descriptions, and may have greater ability at identifying functional similarity across floral species (Abrahamczyk et al. 2017), there is a need to assess whether defining pollination syndromes using quantitative trait measurements leads to conclusions that are consistent with the conclusions that would be reached by using categorical trait descriptions.

Across the pollination biology literature, the predictive power of pollination syndromes has received mixed support (e.g. Danieli-Silva et al. 2012; Guzmán et al. 2017; Johnson \& Wester 2017; Lázaro et al. 2008; Liu \& Huang 2013; Mayfield et al. 200I; Quintero et al. 2017; Rodrigues et al. 2018). Many comparative studies have found support for the pollination syndrome concept (e.g. Abrahamczyk et al. 2017; Armbruster et al. 20I I; Danieli-Silva et al. 20I2; Fenster et al. 2015; Johnson 2013; Lagomarsino et al. 2017; MarténRodríguez et al. 2009; Murúa \& Espíndola 2015; Reynolds et al. 2009; Wilson et al. 2004; Wolfe \& Sowell 2006), while others have not supported the predictive power of pollination syndromes across taxa (e.g. Fishbein \& Venable 1996; Kingston \& McQuillan 2000; Li \& Huang 2009; Maruyama et al. 2013; Ollerton et al. 2009; Prieto-Benítez et al. 2015; Valdivia \& Niemeyer 2006; Waser et al. 1996). A potential reason for this mixed support may be that pollination syndromes are predictive in species highly dependent on pollinators for reproduction, but not in those species less dependent on pollinators. For example, pollinator-mediated selection on floral traits may be stronger in self-incompatible (SI) species, than in self-compatible (SC) species, as autogamy can provide SC plants with reproductive assurance when pollinator reliability is low (Rosas-Guerrero et al. 20I4 Moriera-Hernandez \& Muchhala 2019; also see Anderson et al. 2010). As a result, floral traits may be more predictive of pollinators in SI species than in SC species (Rosas-Guerrero et al. 20I4). Furthermore, as plants with high pollinator specialization (i.e. plant species that use one or a small number of pollinator functional groups) may have floral traits more closely adapted to their pollinator type than generalist species (i.e. plant species that utilize multiple pollinator functional groups), the pollination syndrome concept may be more consistently predictive in specialist compared to generalist species (Ashworth et al. 20I5; Johnson 2013). Given the numerous factors that may affect the ability of floral traits to predict pollinators, more research on the predictive ability of the pollination syndrome concept is needed, especially in species rich clades with a diversity of pollination systems.

Onagraceae - the evening primrose family, one of the major plant radiations in western North America (Raven 1979; Raven \& Gregory 1972; Straley 1977) - is an ideal group in which to test the predictive ability of pollination syndromes. The genus Oenothera is a model system for studying plant reproductive biology and floral evolution, with a wealth of literature describing Oenothera taxonomy and phylogenetics (Krakos 20I I; Krakos et al. 20I4; Krakos et al. accepted; Raven 1988; Raven \& Gregory 1972; Wagner et al. 2007; Wagner et al. 2013). Oenothera is a species rich, monophyletic group, with a diversity of floral traits (e.g. Fig. I) and a wide range of pollination systems (e.g. bee, bird, butterfly, wasp, moth, antlion, fly, beetle, and hawkmoth 
pollination), despite ancestral Oenothera likely being primarily moth pollinated (Clinebell et al. 2004; Krakos \& Fabricant 20I4; Moody-Weis \& Heywood 200I; Nonnenmacher 1999; Raven 1979; Raven \& Gregory 1972; Straley 1977; Wagner et al. 2007). Furthermore, Oenothera pollination systems exist on a gradient of specialization (Krakos \& Fabricant 20I4), and the breeding systems of Oenothera species have undergone multiple independent transitions from SI to SC (Krakos et al. 2014; Krakos et al. accepted; Raven \& Gregory 1972; Wagner et al. 2007). Numerous studies have provided detailed empirical data on the pollination systems of Oenothera taxa that show diverse floral forms (Clinebell et al. 2004; Krakos \& Fabricant 20I4; Moody-Weis \& Heywood 200I; Nonnenmacher 1999; Raven 1979; Raven \& Gregory 1972; Straley 1977), thus providing an opportunity to rigorously test the pollination syndrome concept comparatively across Oenothera species.

Here, we test the predictive ability of pollination syndromes by evaluating the correspondence between floral traits and pollinators in 54 Oenothera species. Toward this aim, we map Oenothera floral traits into morphospace (i.e. phenotype space) - a technique increasingly recognized as having applicability to angiosperm eco-evolutionary studies (Chartier et al. 20I4) - and compare observed pollination data to pollinators predicted by the pollination syndrome concept. We ask the following questions:

I. Do Oenothera species fit the traditional, categorical pollination syndromes of Faegri and van der Pijl (1979)? We predict that Oenothera species will form groups that correspond to their main pollinators when using categorical floral trait measurements, consistent with the traditional pollination syndromes of Faegri and van der Pijl (I979).

2. When using quantitative floral trait measurements, do Oenothera species form groups that correspond to their main pollinators? We predict that Oenothera species will form groups that correspond to their main pollinators when using quantitative floral trait measurements.

3. Does pollinator specialization affect (a) how close Oenothera species are to traditional pollination syndromes in morphospace and (b) how accurately these traditional pollination syndromes predict primary pollinators? We predict greater pollinator specialization will be associated with Oenothera species falling closer to traditional pollination syndromes in morphospace and these syndromes accurately predicting primary pollinators more frequently.

4. Does breeding system affect (a) how close Oenothera species are to traditional pollination syndromes in morphospace and (b) how accurately these traditional pollination syndromes predict primary pollinators? We predict that SI Oenothera species will fall closer to traditional pollination syndromes in morphospace and that these syndromes will accurately predict primary pollinators more frequently, compared to SC Oenothera species.

Through asking these questions, this study helps elucidate the applicability of the pollination syndrome concept across taxa, by (i) assessing whether traditional, categorical floral trait descriptions and quantitative floral trait measurements similarly predict main pollinators in Oenothera and (ii) testing whether certain ecological characteristics promote adherence to the traditional pollination syndrome concept in Oenothera. Determining the predictive ability of pollination syndromes across diverse taxa is essential for understanding the role of pollinators in driving floral trait convergence.

\section{MATERIALS AND METHODS}

\section{Pollinator Data and Floral Traits}

We used the 54 species of Oenothera in Subclade B (Levin et al. 2004) for this study. This clade has a diversity of floral forms and species that are characterized by multiple pollination systems. Krakos and Fabricant (20I4) give detailed pollination data for 26 of these species - including visitation, pollen load, and stigma contact of visitors - that we use here. For the remainder of these species, the main pollinator group comes from published pollination studies (Clinebell et al. 2004; Moody-Weiss \& Heywood 200I; Nonnenmacher 1999) and data on plant-pollinator associations at the Missouri Botanical Garden (RR Clinebell unpublished data, same methodology as Krakos \& Fabricant 20I4). Pollinators were determined using both visitation and pollen load data, and main pollinators were considered those that contributed to $95 \%$ of the total pollen flow. These pollinators were then grouped into functional groups of similar species and sizes following Fenster et al. (2004) and Krakos and Fabricant (20I4), for use in the pollination syndrome analyses described below.

Question 1 - Traditional Pollination Syndromes of Faegri and van der Pijl

To evaluate the predictive power of Faegri and van der Pijl's (1979) traditional pollination syndromes, we first created a morphospace using the categorical floral traits of these syndromes. While Faegri and van der Pijl (1979) originally described II pollination syndromes, the traits for their hawkmoth and moth syndromes have been found to be indistinguishable (Ollerton et al. 2009). Accordingly, we combined Faegri and van der Pijl's (1979) hawkmoth and moth syndromes, and used the remaining IO syndromes in our analyses: bat, bee, beetle, bird, butterfly, fly, hawkmoth/moth, carrion fly, small non-flying mammal, and wasp. The resultant matrix of these traditional pollination syndrome traits is a modified version of Ollerton et al. (2009), which gives different versions of each traditional pollination syndrome (e.g. bee 1 , bee 2 , etc.). This creates a broader, more realistic definition of each traditional pollination syndrome by capturing the variability of floral traits associated with a syndrome (e.g. a bee syndrome can have white or yellow flowers). Following Ollerton et al. (2009), we used a multiple trait vector approach of 537 vectors across 10 syndromes, with each trait scored as present (score of $\mathrm{I}$ ) or absent (score of 0). However, as several traits scored by Ollerton et al. (2009) are not applicable to Oenothera, we modified how the syndromes are characterized to include only the following nine traits, which are all applicable to Oenothera: color at anthesis (yellow, white, red, pink, green, purple, brown, blue, orange), scent (sweet, fruity, fresh, musty, sour, decay, none), flower shape (dish, bell/funnel, trumpet, tube), symmetry (actinomorphic, zygomorphic), orientation (pendant, upright, 


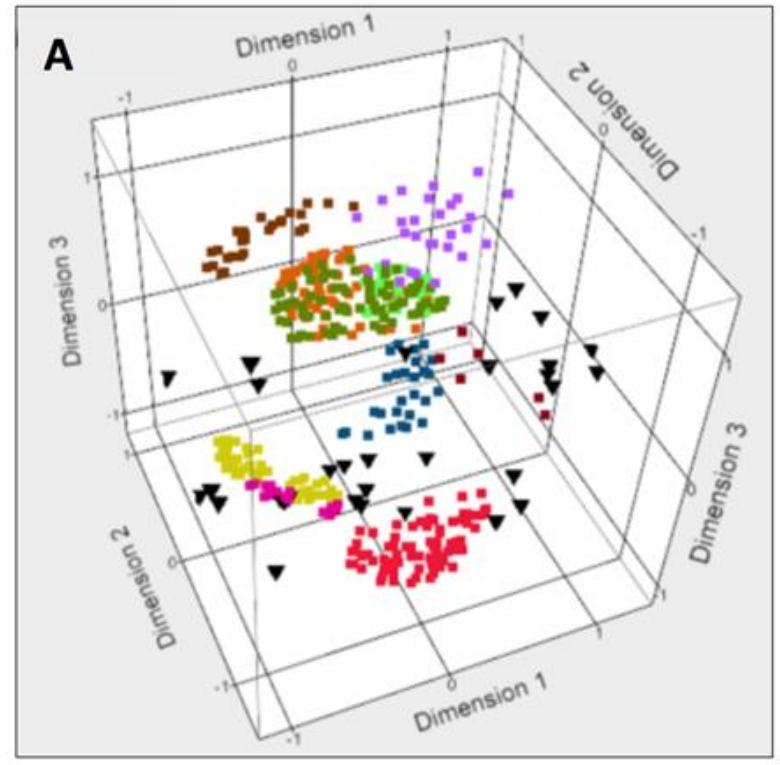

\section{$\boldsymbol{\nabla}$ Oenothera species}

Fly

Bat

- Carrion Fly

Bee

Butterfly

1 Bird

Beetle

Mammal

Moth/Hawkmoth

Wasp

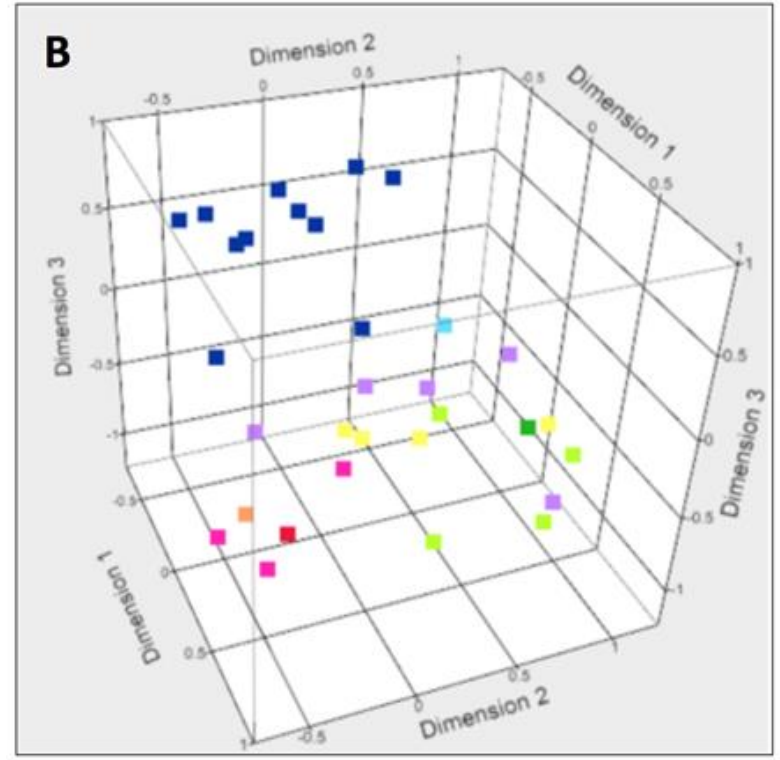

\begin{tabular}{|} 
Xanthocoryne \\
Peniophyllum \\
Paradoxus \\
Megapterium \\
Leucocoryne \\
Kneiffia \\
Hartmannia \\
Gauropsis \\
Gaura
\end{tabular}

FIgURE 2. Non-metric multidimensional scaling (NMDS) ordination of Oenothera floral traits. (A) Rectangular points are the 537 traditional pollination syndromes, colored by pollination system; black triangular points are the 54 Oenothera species. (B) The 54 Oenothera species, colored by section, to depict phylogenetic clustering in morphospace. Plots are rotated to increase visibility of points. horizontal), brightness (dull, vivid), anthesis time (day, night), nectar presence (present, absent), and nectar location (hidden, accessible) (see Supplementary Data Table I for full matrix). We then used these traditional pollination syndrome traits to score the 54 Oenothera species such that each species was described by a vector of 35 ones and zeroes (see Supplementary Data Table 2 for full matrix). These analyses were carried out in PC-ORD (McCune \& Mefford 2006).

To determine whether the different vectors for each of the I0 traditional syndromes grouped into discrete groups, we used formal ordinations using non-metric multidimensional scaling (NMDS) (Ollerton et al. 2009). We used NMDS for this analysis because it is appropriate for binary data, makes no assumptions about the distribution of variables, and creates multivariate space in which similar objects are close to one another (McCune \& Mefford 2006; McCune \& Grace 2002). We used a Sorensen's index (Bray-Curtis) to express the distance relationships between the traditional pollination syndromes described by the binary data set. NMDS was used to find the best dimensional representation of the distance matrix. The NMDS analyses started with 250 runs of real data, which were then compared with a Monte Carlo test with 250 ordinations of randomized data. Mean stress did not decline after three dimensions, and so a three-dimensional space was selected for the analyses (McCune \& Grace 2002). We then ran the final solution and assessed the stability of this solution by examining a Scree plot (final stress versus the number of dimensions), and the final stability reported from the NMDS output. We assessed the final stress from the NMDS using Kruskal's stress formula and Clarke's rule of thumb (McCune \& Grace 2002).

This ordination of the traditional pollination syndromes created a three-dimensional space with each traditional syndrome represented by a cluster of the multiple trait combinations (Fig. 2A). Using these results and the matrix that scored the floral traits of the 54 Oenothera species, we 
used NMDS Scores algorithm in PC-ORD 5.I4 to calculate co-ordinates for the Oenothera species in that morphospace. Then, we calculated the Euclidean distance for each species, which is the distance between each Oenothera species and the nearest traditional pollination syndrome. A shorter Euclidean distance indicates greater correspondence between an Oenothera species' floral traits and a traditional pollination syndrome. To determine how accurately the traditional pollination syndromes of Faegri and van der Pijl (1979) predict observed pollinators, we compared the predicted pollinators from these analyses to the primary pollinators observed in our ecological data (i.e. predicted pollinator does or does not match observed primary pollinator).

\section{Question 2 - Pollination Syndromes Using Quantitative Floral Trait Measurements}

It may be that quantitative morphological floral measurements are better predictors of pollinator type than Faegri and van der Pijl's (1979) traditional, categorical floral traits. To determine whether Oenothera species form groups based on quantitative floral traits that correspond to their main pollinators, we measured floral tube length, floral tube mouth width, corolla span, stamen length, and style length of individuals from each of the 54 Oenothera species. We took these measurements on I0-15 flowers per species, with each flower sampled from a different plant, and represented each trait per species as an average. For $O$. deserticola, $O$. canescens, $O$. rosea, $O$. speciosa, $O$. texensis, $O$. epilobiifolia, $O$. multicaulis, O. seifrizii, O. dissecta, O. kunthiana, O. orizabae, O. tetraptera, O. brachycarpa, O. coryi, O. howardii, $O$. spachiana, O. anomala, O. boquillensis, O. cinerea ssp. parksii, $O$. filipes, and $O$. mckelveyae, we used herbarium sheets from the Missouri Botanical Garden to make these measurements. All other measurements were taken from the plant populations used for pollinator data collection (Krakos \& Fabricant 20I4; Krakos et al. 2014) or with greenhouse populations. We tested whether Oenothera form quantitative floral trait groups using principle component analyses (PCA), a method commonly employed by studies that infer pollination syndromes using quantitative traits (e.g. Lagomarsino et al. 2017; Muchhala 2006; Murúa \& Espíndola 2015; Tripp \& Manos 2008; Whittall \& Hodges 2007). We log transformed our data and conducted a PCA using JMP, Version 8.0 (JMP 2009).

\section{Question 3 - Specialist versus Generalist Oenothera}

Floral species with specialist pollination systems may have more targeted selection on floral traits than species with generalist pollination systems (Ashworth et al. 2015). To evaluate whether degree of pollinator specialization affects adherence to the pollination syndrome concept in Oenothera, we first assessed whether pollinator specialization affects how close Oenothera species fall to the traditional pollination syndromes of Faegri and van der Pijl (1979) in morphospace. To accomplish this, we assigned each Oenothera species a specialization score (i.e. S-score), which equals the minimum number of pollinating taxa that account for $95 \%$ of an Oenothera species' pollen flow; S-scores were taken from Krakos and Fabricant (20I4), as well as an unpublished data set at the Missouri Botanical Garden for O. coloradoensis (see Wagner et al. 20I3). We then ran a linear regression, with S- score as the predictor variable and Euclidean distance from the nearest pollination syndrome as the response variable, to test whether pollinator specialization impacts how close Oenothera species are to traditional pollination syndromes in morphospace. Prior to analysis, we normalized residuals by transforming S-score and Euclidean distance by adding I and subsequently calculating the natural logarithm (ln) of each value.

Following analysis of how specialization affects the distance between Oenothera species and traditional pollination syndromes in morphospace, we assessed whether specialization affects how accurately an Oenothera species' closest pollination syndrome predicts its observed primary pollinator. To accomplish this, we scored each Oenothera species for traditional syndrome predictability, i.e. whether its closest traditional pollination syndrome accurately predicts its primary pollinator. Specifically, we used a binary scoring system, whereby an Oenothera species received a score of I if its closest traditional pollination syndrome accurately predicted its main pollinator (i.e. the pollinator type contributing at least $95 \%$ of pollen flow) or a score of 0 if its closest traditional syndrome did not predict its main pollinator. We then ran a logistic regression, with $\mathrm{S}$-score as the predictor variable and traditional syndrome predictability as the response variable. All question 3 analyses were performed with 27 Oenothera species, as specialization data was not available for all 54 species used in the first two questions. Analyses were performed with RStudio (ver. $0.99 .902)$.

Question 4 - Self-Incompatible versus SelfCompatible Oenothera

As floral species that are self-incompatible (SI) are more reliant on pollinators for reproduction than are selfcompatible (SC) species, breeding system may affect adaptation of floral traits to certain pollinator groups (RosasGuerrero et al. 2014). To evaluate whether breeding system affects adherence to the pollination syndrome concept in Oenothera, we first assessed whether SI Oenothera species fall closer to the traditional pollination syndromes of Faegri and van der Pijl (1979) in morphospace than do SC Oenothera species. To accomplish this, we ran a Welch's $t$-test, with breeding system (SI or SC) as the predictor variable and Euclidean distance as the response variable. Prior to analysis, we transformed Euclidean distance by adding I and subsequently calculating the $\ln$ of each value.

Following analysis of how breeding system affects the distance between Oenothera species and traditional pollination syndromes in morphospace, we assessed whether breeding system affects how accurately an Oenothera species' closest pollination syndrome predicts its primary pollinator. To accomplish this, we performed a two-proportions z-test, with breeding system as the predictor variable and traditional syndrome predictability ( $\mathrm{I}=$ accurate prediction; $0=$ inaccurate prediction) as the response. All question 4 analyses were performed with all 54 Oenothera species used in the first two questions. Analyses were performed with RStudio (ver. $0.99 .902)$. 


\section{RESULTS}

\section{Question 1 - Traditional Pollination Syndromes of Faegri and van der Pijl}

Ordination using non-metric multidimensional scaling (NMDS) of the traditional pollination syndromes of Faegri and van der Pijl (1979) produced a well-resolved threedimensional morphospace that accounted for nearly $75 \%$ of the variance of the among-syndrome variation (axis I $R^{2}=$ 0.16 , axis $2 R^{2}=0.28$, axis $3 R^{2}=0.29$, cumulative $R^{2}=$ 0.74 ). After 279 iterations the instability was 0.00 , and the final stress for the three-dimensional solution was I5.3I. Most ecological community data sets have solutions with stress between $\mathrm{IO}$ and 20, and this data set falls within this range (Clarke 1993). In agreement with the results for the traditional pollination syndromes used by Ollerton et al. (2009), we also find that the traditional syndromes, which had multiple versions for each pollinator type, group into discrete areas of morphospace without overlap (Fig. 2A). For example, all of the "bee" syndrome vectors group together, while all of the "moth" syndrome vectors group together and do not overlap with the "bee" syndrome. However, some syndrome groups are closer together, for example, non-flying mammal and bat.

If Oenothera species conform to the traditional pollination syndromes of Faegri and van der Pijl (1979), with the floral trait combination for a given species being similar to one of the defined traditional syndromes, we expect that Oenothera species to fall within the cluster of a traditional syndrome. These results show that these 54 Oenothera species do not fall within any of the morphospace clusters that represent traditional pollination syndromes (Fig. 2A). There is no grouping in the morphospace between the sections of Oenothera that reflects phylogenetic relatedness. Sections that are sister to one another are not near each other in morphospace. However, Oenothera do show some clustering within the sections of the genus (Fig. 2B). For instance, 24 of the 26 species in section Gaura cluster together and the four species in section Megapterium occupy the same morphospace.

When we calculated the nearest traditional pollination syndrome for each Oenothera species, and compared that to current ecological pollinator data, we found that observed primary pollinators were accurately predicted by traditional pollination syndromes for $48.2 \%$ of species (Table I). Several species had equal Euclidean distance values from multiple traditional pollination syndrome vectors, in which case, we scored their pollination syndrome as not accurately predicting their observed primary pollinator. The predictability of traditional pollination syndromes varied (Table I). Plants observed to be primarily moth-pollinated and primarily butterfly-pollinated were the most accurately predicted (moth $69.7 \%$ accuracy, 23/33 species; butterfly 100.0\% accuracy, I/I species). Bird-pollinated plants were accurately predicted $25.0 \%$ of the time ( $1 / 4$ species), while bee-pollinated plants were accurately predicted $26.7 \%$ of the time (4/I5 species). Fly-pollinated and beetle-pollinated plants were never accurately predicted (0/2 and $0 / I$ species respectively).
Furthermore, pollinator predictability was more successful in some sections of Oenothera than others. In subsection Megapterium, three of the four (75.0\%) taxa were accurately predicted by the traditional pollination syndromes, and 18 of the $26(69.2 \%)$ taxa in subsection Gaura were accurately predicted by the traditional pollination syndromes. The one species in subsection Paradoxus had its pollination system accurately predicted. The pollination systems for sections Kneiffia, Gauropsis, and Peniophyllum were never predicted accurately $(0 / 7,0 / \mathrm{I}$, and $0 / \mathrm{I}$ species respectively) and only one of five $(20.0 \%)$ species in section Hartmannia had their pollination system accurately predicted. One in four $(25.0 \%)$ taxa of section Xanthocoryne and two in five (40.0\%) taxa of section Leucocoryne had accurately predicted pollination systems.

Question 2 - Pollination Syndromes Using Quantitative Floral Trait Measurements

For all 54 Oenothera species examined, the floral trait measurement data (i.e. floral tube length, floral tube mouth width, corolla span, stamen length, style length) used in the principle component analyses (PCA) are given in Table 2. The first two PCA axes explained $78.87 \%$ and $10.87 \%$ of the variance in the data (Fig. 3). Although approximately $90 \%$ of the data is explained with the first two axes, the PCA is unable to give sufficient resolution to discern any grouping of the Oenothera species that might correspond to a pollination syndrome. The eigenvector coefficients of axis $\mathrm{I}$ are all positive, which suggests an allometric relationship among the variables. The correlations of variables on PCA axes are given in Table 3. Axis I shows some differentiation between species with long floral tubes and those without. The species that demonstrate some clustering are in section Megapterium, which are taxa that all have much longer floral tubes than the other Oenothera. Most of the variance for axis 2 is explained by "floral tube mouth width"; however, there is no discernable grouping of species by this quantitative trait. Despite this partial differentiation, unlike the NMDS results, the PCA overall does not provide resolution sufficient to discern groupings of taxa that correspond to pollination syndromes.

\section{Question 3 - Specialist versus Generalist Oenothera}

We did not find support for pollinator specialization (i.e. S-score) affecting how close Oenothera species fall to traditional pollination systems in morphospace. Our linear regression explained none of the variance in Euclidean distance scores $\left(R^{2}=0.000\right)$ and was not statistically significant $\left(F_{1,26}=0.003, p=0.958\right)$ (Fig. $\left.4 \mathrm{~A}\right)$. Furthermore, we did not find support for pollinator specialization affecting how accurately traditional pollination syndromes predict primary pollinators of Oenothera. Our logistic regression was not statistically significant $(p=0.707)$ (Fig. 4B).

\section{Question 4 - Self-Incompatible versus Self- Compatible Oenothera}

We did not find support for breeding system affecting how close Oenothera species fall to traditional pollination systems in morphospace. Our Welch's $t$-test did not find statistically significant differences in Euclidean distance between self-incompatible (SI) and self-compatible (SC) 
TABLE I. A comparison of the predicted pollinator and the observed primary pollinators for the 54 Oenothera species. Predicted pollinators are determined by the closest traditional pollination syndrome to the Oenothera species in morphospace. The primary pollinators are determined by ecological data.

\begin{tabular}{|c|c|c|c|}
\hline Section & Species & Predicted Pollinator & Current Main Pollinator \\
\hline Gauropsis & O. canescens & bird & moth/hawkmoth \\
\hline Hartmannia & O. deserticola & butterfly & bee \\
\hline Hartmannia & O. platanorum & bird & bee \\
\hline Hartmannia & O. rosea & butterfly & bee \\
\hline Hartmannia & O. speciosa & moth/hawkmoth & moth/hawkmoth \\
\hline Hartmannia & O. texensis & bird & bee \\
\hline Xanthocoryne & O. epilobiifolia s. epilobiifolia & fly & bird \\
\hline Xanthocoryne & O. epilobiifolia s. cuphrea & bird & bird \\
\hline Xanthocoryne & O. multicaulis & fly & bird \\
\hline Xanthocoryne & O. seifrizii & fly & bird \\
\hline Leucocoryne & O. dissecta & moth/hawkmoth & moth/hawkmoth \\
\hline Leucocoryne & O. kunthiana & beetle & moth/hawkmoth \\
\hline Leucocoryne & O. Iuciae-julianae & moth/hawkmoth & moth/hawkmoth \\
\hline Leucocoryne & O. orizabae & beetle & moth/hawkmoth \\
\hline Leucocoryne & O. tetraptera & beetle & moth/hawkmoth \\
\hline Paradoxus & O. havardii & moth/hawkmoth & moth/hawkmoth \\
\hline Megapterium & O. brachycarpa & moth/hawkmoth & moth/hawkmoth \\
\hline Megapterium & O. coryi & moth/hawkmoth & moth/hawkmoth \\
\hline Megapterium & O. howardii & moth/hawkmoth & moth/hawkmoth \\
\hline Megapterium & O. macrocarpa s. macrocarpa & bird & moth/hawkmoth \\
\hline Peniophyllum & O. linifolia & bird & none/fly/bee \\
\hline Kneiffia & O. fruticosa s. fruticosa & butterfly & bee \\
\hline Kneiffia & O. fruticosa s. glauca & butterfly & bee \\
\hline Kneiffia & O. riparia & butterfly & bee \\
\hline Kneiffia & O. perennis & bird & bee \\
\hline Kneiffia & O. pilosella & butterfly & bee \\
\hline Kneiffia & O. sessilis & butterfly & none \\
\hline Kneiffia & O. spachiana & bird & none \\
\hline Gaura & O. anomala & moth/hawkmoth & moth/hawkmoth \\
\hline Gaura & O. glaucifolia & fly & bee/fly/beetle \\
\hline Gaura & O. curtiflora & beetle & none \\
\hline Gaura & O. arida & beetle & moth/hawkmoth \\
\hline Gaura & O. suffrutescens & moth/hawkmoth & moth/hawkmoth \\
\hline Gaura & O. boquillensis & moth/hawkmoth & moth/hawkmoth \\
\hline Gaura & $O$. cinerea s. cinerea & moth/hawkmoth/beetle & moth/hawkmoth \\
\hline Gaura & O. cinerea s. parksii & moth/hawkmoth & antlion \\
\hline Gaura & O. calcicola & moth/hawkmoth & moth/hawkmoth \\
\hline Gaura & O. filipes & moth/hawkmoth & moth/hawkmoth \\
\hline Gaura & O. mckelveyae & moth/hawkmoth & moth/hawkmoth \\
\hline Gaura & O. sinuosa & moth/hawkmoth/beetle & moth/hawkmoth \\
\hline Gaura & O. hispida & moth/hawkmoth & moth/hawkmoth \\
\hline Gaura & O. coloradoensis & moth/hawkmoth & moth/hawkmoth \\
\hline
\end{tabular}


Tab. continued

\begin{tabular}{llll}
\hline Section & Species & Predicted Pollinator & Current Main Pollinator \\
\hline Gaura & O. dodgeniana & moth/hawkmoth & moth/hawkmoth \\
Gaura & O. demareei & bee & bee \\
Gaura & O. filiformis & moth/hawkmoth & moth/hawkmoth/bee \\
Gaura & O. gaura & moth/hawkmoth & moth/hawkmoth \\
Gaura & O. lindheimeri & bee & bee/butterfly \\
Gaura & O. hexandra & moth/hawkmoth & moth/hawkmoth \\
Gaura & O. podocarpa & moth/hawkmoth & moth/hawkmoth \\
Gaura & O. patriciae & moth/hawkmoth & moth/hawkmoth \\
Gaura & O. simulans & beetle & moth/hawkmoth \\
Gaura & O. suffulta & moth/hawkmoth & moth/hawkmoth \\
Gaura & O. nealleyi & moth/hawkmoth & moth/hawkmoth/bee \\
Gaura & O. triangulata & beetle & moth/hawkmoth \\
\hline
\end{tabular}

species ( $p=0.1$ I2) (Fig. 5A); mean Euclidean distance of SC and SI species is $0.363( \pm 0.018 \mathrm{SE})$ and 0.407 ( $\pm 0.02 \mathrm{I} \mathrm{SE})$ respectively. Furthermore, we did not find support for breeding system affecting how accurately traditional pollination syndromes predict primary pollinators in Oenothera. Our two-proportions z-test was not statistically significant $(p=0.107)$ (Fig. 5B); mean traditional syndrome predictability of SC and SI species is $0.367( \pm 0.089 \mathrm{SE})$ and 0.625 ( \pm 0.IOI SE) respectively.

\section{DISCUSSION}

The main goal of this study was to assess the predictive ability of pollination syndromes in Oenothera, using both the traditional pollination syndromes of Faegri and van der Pijl (1979) and quantitative floral trait measurements. Across the literature, the predictive ability of pollination syndromes has received mixed support; the pollination syndrome concept has been supported in some taxa (e.g. Rosas-Guerrero et al. 20I4; Johnson \& Wester 2017) and has failed to be supported in others (e.g. Ollerton et al. 2009). By evaluating the correspondence between floral traits and primary pollinator in 54 Oenothera species, we do not find support for the pollination syndrome concept across Oenothera following the traditional pollination syndromes of Faegri and van der Pijl (I979) (Question I). Furthermore, we do not find support for the pollination syndrome concept in Oenothera when quantitative floral trait measurements are used, as such measurements did not cluster in morphospace (Question 2). This study adds to the pollination biology literature by testing the pollination syndrome concept in a species rich, monophyletic clade with high ecological diversity. Oenothera is comprised of species across the Americas with high variation in pollination systems and pollinator specialization (Krakos $\&$ Fabricant 20I4), some of which are self-incompatible (SI), while others are self-compatible (SC) (Krakos et al. 20I4). While we do not find support for pollinator specialization (Question 3) or breeding system (Question 4) affecting adherence to the pollination syndrome concept using the traditional syndromes of Faegri and van der Pijl (1979), we do find that floral traits - as defined by these traditional syndromes - are predictive of primary pollinators more frequently in certain Oenothera clades and for Oenothera species that are predominantly pollinated by moths. Collectively, these results suggest that the pollination syndrome concept cannot be generalized across taxa and that evolutionary history should be considered when evaluating pollination syndromes in different clades.

When applying the pollination syndrome concept, pollination biologists have often used the traditional pollination syndromes described by Faegri and van der Pijl (1979). While we find that these syndromes segregate into discernable clusters in morphospace, our 54 Oenothera species do not fall within or near these traditional syndrome clusters (Fig. 2A). This is in agreement with Ollerton et al. (2009), who also found that plant species do not fall within these traditional pollination syndrome clusters in morphospace. Comparing observed pollination data to the primary pollinator predicted by the nearest traditional pollination syndrome, we find that the predicted pollinator matches the observed primary pollinator in less than half (48.2\%) of our Oenothera species. This is slightly more successful than the results of Ollerton et al. (2009), who found that the primary pollinator was successfully predicted by the nearest traditional syndrome one-third of the time. One reason for the higher predictability with our data may be that our pollination data are based on both visitation and pollen load, whereas Ollerton et al. (2009) used only flower visitor observations to determine pollinators. Flower visitation alone is an unreliable indicator of pollinator effectiveness and visitor observations can overestimate the number of actual pollinators (Krakos \& Fabricant 20I4; Ashworth et al. 2015; King et al. 2013). Moving beyond the traditional pollination syndromes of Faegri and van der Pijl (1979), many studies have tested the pollination syndrome concept using quantitative floral trait measurements (e.g. Lagomarsino et al. 2017; Muchhala 2006; Murúa \& Espíndola 2015; Tripp \& Manos 2008; Whittall \& Hodges 2007). When applying this approach to Oenothera, our quantitative floral traits also did not form discernable clusters (Fig. 3). This suggests that, for Oenothera, the categorical floral traits of traditional pollination syndromes better represent floral form 
TABLE 2. Mean measurements of flower morphology ( $\mathrm{mm}$ ) for 54 species of Oenothera.

\begin{tabular}{|c|c|c|c|c|c|c|}
\hline Section & Species & $\begin{array}{l}\text { Floral Tube } \\
\text { Length }\end{array}$ & $\begin{array}{l}\text { Floral Tube } \\
\text { Mouth Width }\end{array}$ & $\begin{array}{l}\text { Corolla } \\
\text { Span }\end{array}$ & $\begin{array}{l}\text { Stamen } \\
\text { Length }\end{array}$ & $\begin{array}{l}\text { Style } \\
\text { Length }\end{array}$ \\
\hline Gauropsis & O. canescens & $\mathrm{I} 2.50$ & 2.00 & 17.00 & 24.50 & 7.00 \\
\hline Hartmannia & O. deserticola & 7.75 & 2.00 & 25.50 & 16.50 & 6.75 \\
\hline Hartmannia & O. platanorum & II. 50 & 2.25 & 23.00 & 15.50 & 6.50 \\
\hline Hartmannia & O. rosea & 6.00 & 2.00 & $\mathrm{I} 4.00$ & 10.25 & 5.00 \\
\hline Hartmannia & O. speciosa & 18.50 & 4.00 & 60.00 & 37.50 & 16.00 \\
\hline Hartmannia & O. texensis & 18.00 & 3.50 & 33.00 & 28.00 & I I. 00 \\
\hline Xanthocoryne & O. epilobiifolia s. epilobiifolia & I I.00 & 5.25 & $\mathrm{I} 4.50$ & 10.25 & 2.25 \\
\hline Xanthocoryne & O. epilobiifolia s. cuphrea & I I.00 & 5.25 & $\mathrm{I} 4.50$ & 10.25 & 2.25 \\
\hline Xanthocoryne & O. multicaulis & 5.75 & 2.75 & 10.50 & 7.25 & 3.25 \\
\hline Xanthocoryne & O. seifrizii & 13.00 & 4.75 & 20.00 & 18.00 & 5.75 \\
\hline Leucocoryne & O. dissecta & 38.50 & 4.50 & 60.00 & 58.50 & 13.50 \\
\hline Leucocoryne & O. kunthiana & 19.50 & 4.00 & 26.00 & 23.00 & 10.00 \\
\hline Leucocoryne & O. Iuciae-julianae & 16.50 & 4.00 & 42.00 & 25.00 & 8.50 \\
\hline Leucocoryne & O. orizabae & 12.00 & 4.00 & 40.00 & 24.00 & 5.00 \\
\hline Leucocoryne & O. tetraptera & 34.00 & 4.75 & 50.00 & 43.00 & I I. .50 \\
\hline Paradoxus & O. havardii & 52.50 & 3.85 & 51.00 & 75.50 & 16.50 \\
\hline Megapterium & O. brachycarpa & 165.00 & 7.50 & 103.00 & $\mathrm{I} 55.00$ & 26.00 \\
\hline Megapterium & O. coryi & 87.50 & 6.50 & 78.00 & $\mathrm{I} 20.00$ & 21.00 \\
\hline Megapterium & O. howardii & 85.00 & 7.00 & 100.00 & $\mathrm{I} 27.50$ & 31.50 \\
\hline Megapterium & O. macrocarpa s. macrocarpa & I05.00 & 8.00 & II 5.00 & $\mathrm{I} 47.50$ & 35.00 \\
\hline Peniophyllum & O. linifolia & 1.50 & 0.10 & 8.00 & $\mathrm{I} .50$ & $\mathrm{I} .50$ \\
\hline Kneiffia & O. fruticosa s. fruticosa & 10.00 & 1.00 & 40.00 & 15.00 & I0.00 \\
\hline Kneiffia & O. fruticosa s. glauca & 12.50 & 1.00 & 35.00 & 16.00 & 10.00 \\
\hline Kneiffia & O. riparia & 13.72 & 1.95 & 31.96 & 13.30 & I I.08 \\
\hline Kneiffia & O. perennis & 6.50 & 1.00 & $\mathrm{I} 5.00$ & 3.50 & 3.50 \\
\hline Kneiffia & O. pilosella & 17.50 & 1.00 & 45.00 & 15.00 & II.00 \\
\hline Kneiffia & O. sessilis & $\mathrm{I} 2.50$ & 1.00 & 29.23 & II.00 & 8.00 \\
\hline Kneiffia & O. spachiana & 7.00 & 1.00 & 19.00 & 5.00 & 5.00 \\
\hline Gaura & O. anomala & 3.40 & 0.50 & 37.00 & 5.25 & I I.50 \\
\hline Gaura & O. glaucifolia & 9.50 & 0.10 & 10.00 & 6.50 & 6.50 \\
\hline Gaura & O. curtiflora & 3.25 & 0.10 & 5.50 & 6.00 & 2.25 \\
\hline Gaura & O. arida & I I.00 & 0.25 & $\mathrm{I} 5.00$ & 20.00 & 4.00 \\
\hline Gaura & O. suffrutescens & 7.50 & 1.00 & I0.00 & $\mathrm{I} 5.50$ & 4.75 \\
\hline Gaura & O. boquillensis & 5.75 & 0.25 & $\mathrm{I} 4.00$ & 10.75 & 3.25 \\
\hline Gaura & O. cinerea s. cinerea & 3.50 & 0.25 & 21.50 & $\mathrm{I} 4.25$ & 8.00 \\
\hline Gaura & O. cinerea s. parksii & 2.75 & 1.00 & 19.00 & $\mathrm{I} 2.50$ & 6.75 \\
\hline Gaura & O. calcicola & 6.00 & 1.00 & 17.50 & $\mathrm{I} 4.25$ & 5.00 \\
\hline Gaura & O. filipes & 4.25 & 0.50 & I5.00 & $\mathrm{I} 3.75$ & 5.75 \\
\hline Gaura & O. mckelveyae & 2.75 & 0.25 & 17.50 & $\mathrm{I} 2.50$ & 7.00 \\
\hline Gaura & O. sinuosa & 3.75 & 1.67 & 21.50 & 15.25 & 8.00 \\
\hline Gaura & O. hispida & 9.00 & 1.00 & 16.00 & 19.00 & 6.25 \\
\hline Gaura & O. coloradoensis & 8.00 & 1.00 & 20.50 & 22.00 & 7.75 \\
\hline Gaura & O. dodgeniana & 8.00 & 1.00 & 24.30 & 25.00 & 7.75 \\
\hline
\end{tabular}


Tab. 2 continued

\begin{tabular}{|c|c|c|c|c|c|c|}
\hline Section & Species & $\begin{array}{l}\text { Floral Tube } \\
\text { Length }\end{array}$ & $\begin{array}{l}\text { Floral Tube } \\
\text { Mouth Width }\end{array}$ & $\begin{array}{l}\text { Corolla } \\
\text { Span }\end{array}$ & $\begin{array}{l}\text { Stamen } \\
\text { Length }\end{array}$ & $\begin{array}{l}\text { Style } \\
\text { Length }\end{array}$ \\
\hline Gaura & O. demareei & 8.50 & 1.00 & 28.00 & 24.50 & $\mathrm{I} 2.50$ \\
\hline Gaura & O. filiformis & 8.75 & 1.00 & 21.50 & 22.75 & 9.00 \\
\hline Gaura & O.gaura & 9.25 & 1.95 & $\mathrm{I} 8.50$ & $\mathrm{I} 3.50$ & 7.50 \\
\hline Gaura & O. lindheimeri & 6.50 & 0.25 & 25.50 & 21.25 & 9.75 \\
\hline Gaura & O. hexandra & 6.00 & 0.25 & I I. 50 & II.75 & 2.90 \\
\hline Gaura & O. podocarpa & 8.00 & 1.70 & I 5.00 & I 5.00 & 5.00 \\
\hline Gaura & O. patriciae & 9.25 & 0.25 & 20.50 & 19.50 & 6.50 \\
\hline Gaura & O. simulans & 5.50 & 0.80 & $\mathrm{I} 2.50$ & 13.25 & 4.25 \\
\hline Gaura & O. suffulta & 10.25 & 2.00 & 10.00 & 24.00 & 7.50 \\
\hline Gaura & O. nealleyi & 15.00 & 2.00 & 13.00 & 29.00 & $\mathrm{I} 0.50$ \\
\hline Gaura & O. triangulata & 4.75 & 0.25 & 8.50 & 9.50 & 2.75 \\
\hline
\end{tabular}

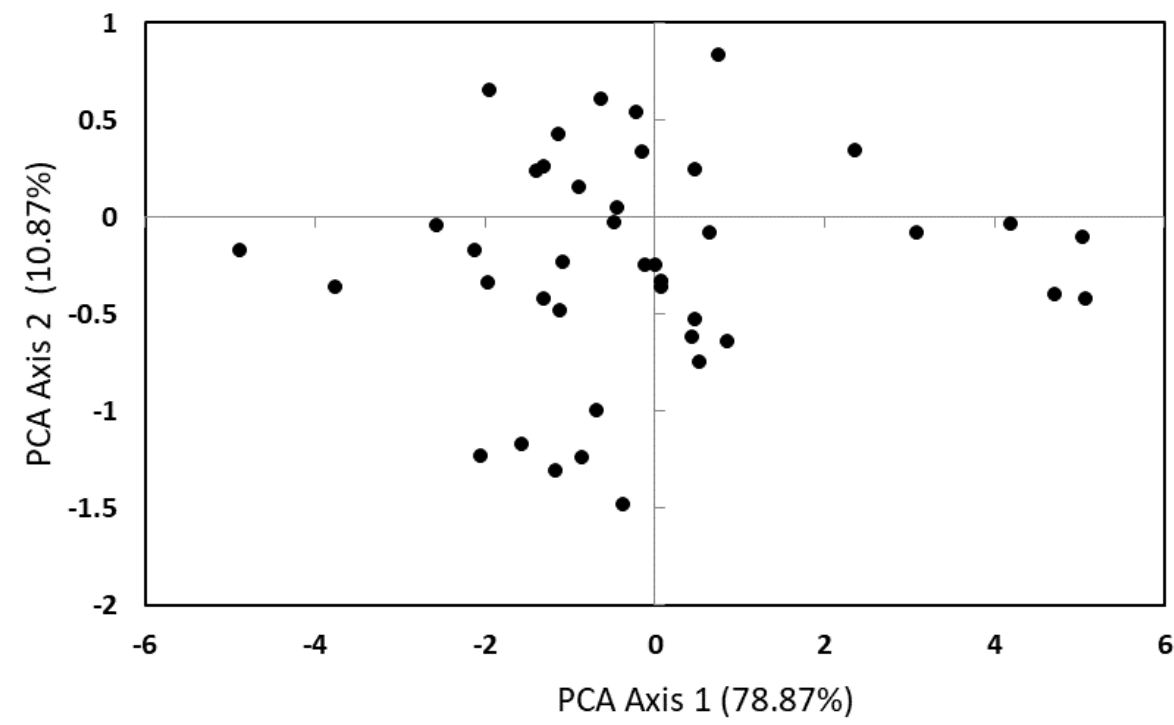

FIGURE 3. Principle component analysis (PCA) of five Oenothera floral trait measurements. convergence, when compared to our quantitative floral traits. However, it is important to note that, if syndromes exist in Oenothera, the five quantitative floral traits we analyzed may not fully capture the breadth of syndrome traits in this group. Indeed, it is possible that pollination syndromes in Oenothera may be best represented by quantitative floral traits, but will only be realized with the inclusion of a greater number of functional traits. Nonetheless, given the clustering of Faegri and van der Pijl's (1979) traditional syndromes in morphospace, and the absence of clustering when using our five measured floral traits, our results suggest that the traditional syndromes are more appropriate to utilize when testing the pollination syndrome concept compared to our quantitative floral traits.

The mixed support for the pollination syndrome concept found across the literature may result from floral traits being predictive of pollinators in certain species, but not in others. Of the Oenothera species examined here, we find that some subsections had higher traditional pollination syndrome predictability, namely Paradoxus (I00.0\%, I/I species),
Megapterium (75.0\%, 3/4 species), and Gaura (69.2\%, I8/26 species). Furthermore, we find species predicted to have moth and butterfly syndromes - which are close to one another in morphospace, typically sharing traits such as long, narrow corolla tubes - were predicted with the highest accuracy (moth 69.7\%, 23/33 species; butterfly 100.0\%, I/I species), while species with other predicted syndromes were predicted with low accuracy (e.g. bird 33.3\%, I/4 species; bee $26.7 \%$, 4/I5 species; fly $0.0 \%, 0 / 2$ species; beetle $0.0 \%, 0 / \mathrm{I}$ species). This is notable as (I) the majority of Oenothera species are moth pollinated (e.g. 33 of the 54 focal Oenothera species in this study), and (2) Oenothera generally have many floral traits that are classically associated with moth pollination (e.g. flower at night, long floral tubes) (Raven \& Gregory 1972; Raven 1988; Wagner et al. 2007), including most species within Paradoxus, Megapterium, and Gaura. In agreement with the broad literature on Oenothera evolutionary history (e.g. Raven I988; Raven \& Gregory 1972; Wagner et al. 2007; Wagner et al. 20I3), these suggest that ancestral Oenothera were moth pollinated. It is possible 
TABLE 3. Eigenvector coefficients for the morphological characters used in the PCA analysis.

\begin{tabular}{lll}
\hline Floral Trait & Axis I & Axis 2 \\
\hline Floral tube length & 0.467 & 0.158 \\
Floral tube mouth width & 0.392 & 0.801 \\
Corolla span & $0.46 \mathrm{I}$ & -0.253 \\
Length of stigma & 0.465 & -0.093 \\
Length of stamen & 0.448 & -0.510 \\
\hline
\end{tabular}

that our results reflect an evolutionary lag between ancestral and contemporary pollinators. In other words, contemporarily moth pollinated Oenothera may follow the pollination syndrome concept more frequently than Oenothera that are pollinated by a different primary pollinator, as sufficient evolutionary time may not have passed to allow divergence in floral traits from the ancestral moth syndrome characters. Fitting with this interpretation, most Gaura are moth pollinated and cluster in morphospace (Fig. 2B); however, certain Gaura are primarily pollinated by bees, flies, or beetles and the Gaura with the least predictability have the most generalist pollination systems. Additionally, the sections with the lowest predictability were those that have floral traits suggestive of moth pollination, but that are pollinated by a different primary pollinator. For example, Kneiffia (0.0\%, $0 / 7$ species) have many floral traits that suggest a moth pollination syndrome; however, Kneiffia open in the morning and are bee pollinated (Krakos \& Fabricant 20I4; Krakos et al. 20I4). This interpretation, that our results reflect an evolutionary lag between ancestral and contemporary pollinators, is concordant with the argument of Li and Huang (2009) that pollination syndromes may not reflect contemporary pollinators when historic pollinators have been replaced.

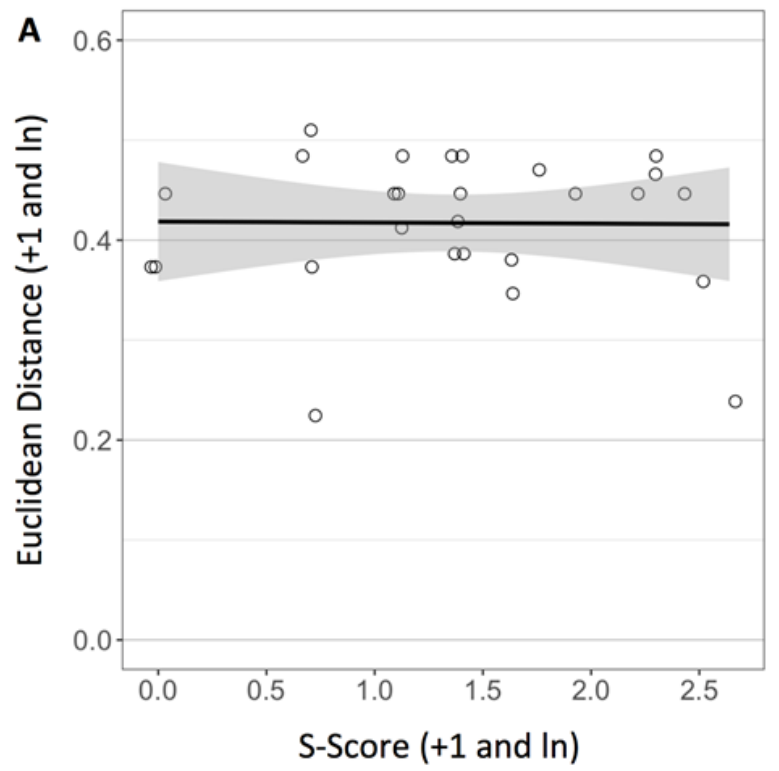

We further tested whether the mixed support for the pollination syndrome concept seen across the literature may result from floral traits predicting primary pollinators more often in species that are highly reliant on certain pollinator groups for reproduction (e.g. highly specialized and/or SI species) as opposed to species less reliant on specific pollinator groups for reproduction (e.g. generalist and/or SC species) (Rosas-Guerrero et al. 2014). In Oenothera, we do not find support for either pollinator specialization or breeding system affecting adherence to the pollination syndrome concept, when using the traditional syndromes of Faegri and van der Pijl (I979) (Figs. 4 and 5). Oenothera is a well-studied clade that is hypothesized to have originated in Central America and then radiated to North and South America (Raven 1988, Munz 1938, Dietrich et al. 1997 Evans et al. 2005 Wagner et al. 2007). It has been found to have highly labile breeding systems; in Subclade B ( 54 species total), there have been 12 to I5 independent transitions from SI to SC (Wagner et al. 2007; Krakos et al. accepted). Evolutionary transitions to SC often occur when pollinators do not reliably transfer conspecific pollen between flowers, thus providing reproductive assurance to plants that have low pollinator fidelity (Moreira-Hernandez \& Muchhala 2019). Consequently, such transitions to SC are thought to promote the diversification of angiosperms, as $\mathrm{SC}$ can be a mechanism of reproductive isolation, when all seed set is from self-pollen (Baker 1955; Barrett 2002). Fitting with the interpretation that our results may reflect an evolutionary lag between ancestral and contemporary pollinators, it is possible that sufficient evolutionary time has not passed since transitions to $\mathrm{SC}$ to allow divergence in floral traits from their SI ancestors. Alternatively, as SC Oenothera are capable of outcrossing, evolutionary pressure may still exist to maintain floral traits for pollinator attraction.

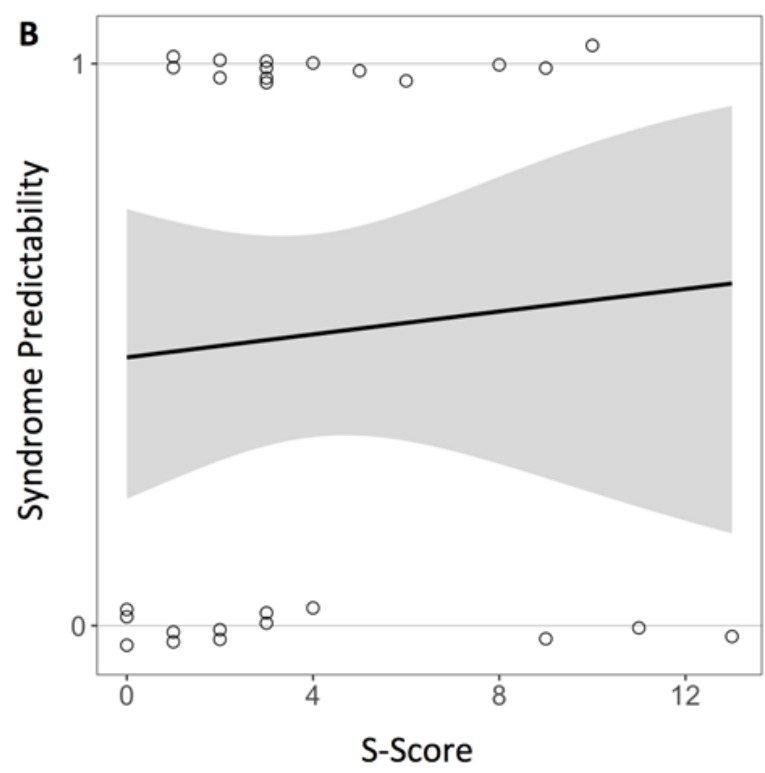

FIGURE 4. Specialization (i.e. S-score) regressed against (A) Euclidean distance (i.e. how close Oenothera floral traits are to a traditional pollination syndrome in morphospace) and (B) whether an Oenothera's closest pollination syndrome accurately predicts its primary pollinator $(\mathrm{I}=$ accurate prediction; $0=$ inaccurate prediction). Gray areas are $95 \%$ confidence intervals. Points are slightly offset to show when multiple points exist for a value. In panel A, the regression depicts the relationship between S-score and Euclidean distance, with both variables $+\mathrm{I}$ and $\mathrm{ln}$ transformed. 

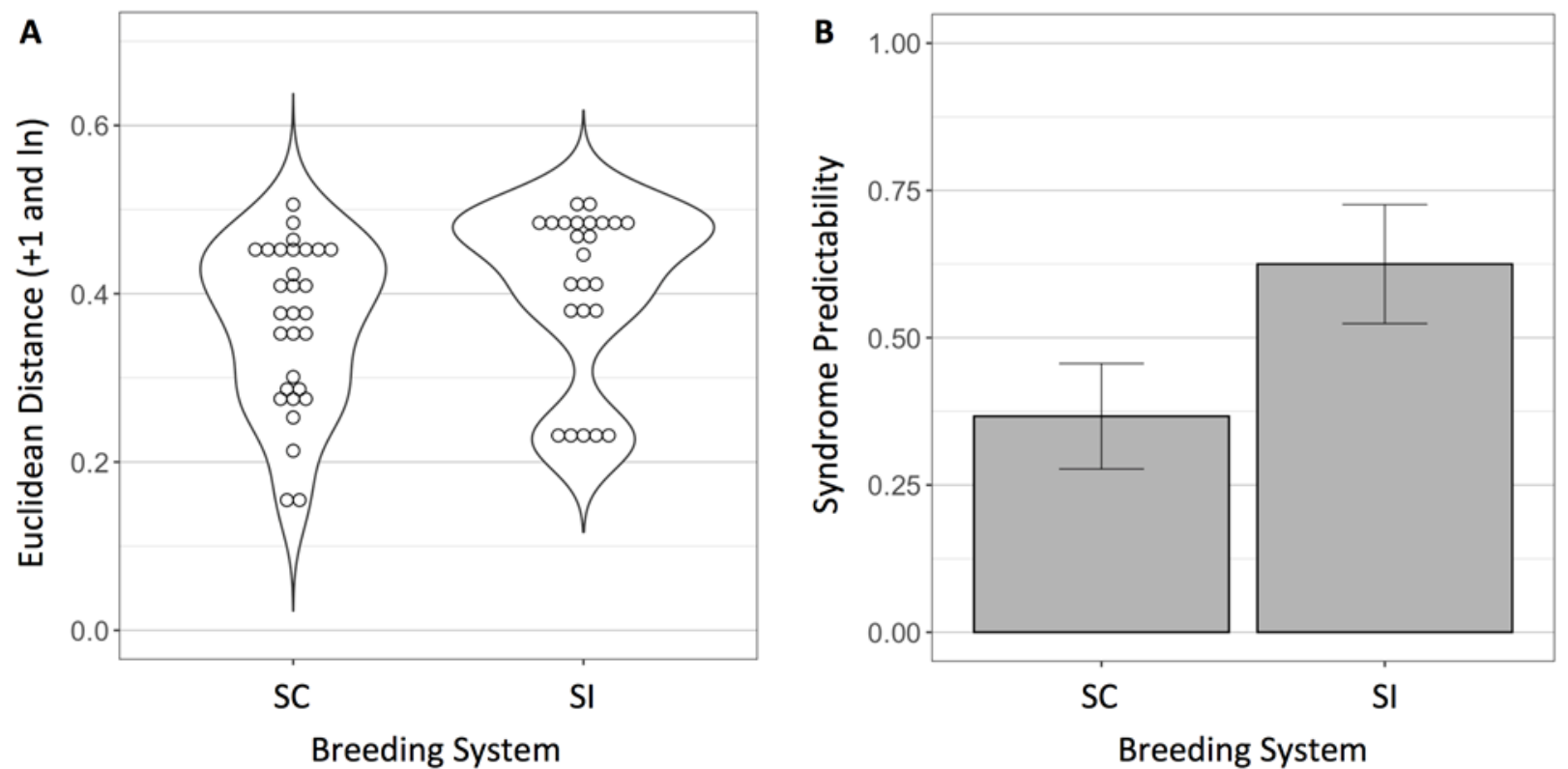

FiguRE 5. Breeding system effects on (A) Euclidean distance (i.e. how close Oenothera floral traits are to a traditional pollination syndrome in morphospace) and (B) whether an Oenothera's closest pollination syndrome accurately predicts its primary pollinator $(\mathrm{I}=$ accurate prediction; $0=$ inaccurate prediction). In panel A, Euclidean distance is $+\mathrm{I}$ and $\ln$ transformed. In panel B, bars are \pm SE. SC $=$ self-compatible; SI $=$ self-incompatible

In addition to an evolutionary lag in pollinators, our results may be partially explained by pollinator stochasticity over shorter temporal intervals. Across time and space, pollinator community composition may change due to multiple factors (e.g. habitat disturbances, range shifts, alterations to phenological timing), thus inducing spatiotemporal variation in the identity of pollinators visiting particular species of flowering plant (e.g. Davila \& Wardle 2008; Burkle \& Alarcon 20II; Lázaro et al. 2008). As these pollinators may vary along multiple trait axes (e.g. functional traits, sensory perception), such spatiotemporal variation can produce high variation in pollination network structure from season to season (Burkle \& Alarcon 20I I; Burkle et al. 20I3). While sustained shifts in pollination network structure may promote floral trait evolutionary change, pollinator stochasticity over short periods may result in plant-pollinator associations that do not follow predictions of the pollination syndrome concept. Thus, defining a plant's primary pollinator from a relatively short time window could lead to a documented plant-pollinator association that does not represent a plant's true primary pollinator that would be captured by long-term monitoring. While we believe our methods for defining observed primary pollinators constituted sufficient sampling across time and space to capture representative associations between our Oenothera species and their true primary pollinators (Krakos \& Fabricant 20I4), we acknowledge that pollinator spatiotemporal stochasticity may have influenced these measures. This consideration raises an important, but often overlooked, question for studies on plant-pollinator interactions; namely, how does the reliability of primary pollinators affect pollination networks and floral evolution. Numerous studies have considered how unreliable transfer of conspecific pollen between flowers (e.g. interspecific pollen transfer) affects floral evolution (e.g. Hildesheim et al. 2019; Kalisz \& Vogler
2003; Moreira-Hernandez \& Muchhala; Opedal et al. 2016) and studies have examined how reliability of floral rewards affects pollinator behavior (e.g. Austin et al. 2019; Dunlap et al. 2017); however, how stochasticity in the presence of pollinators affects floral evolution and the delineation of pollination systems remains a largely understudied topic. Future studies testing the pollination syndrome concept should utilize plant-pollinator data with broad spatiotemporal coverage when defining primary pollinators and consider how pollinator reliability across time and space may influence the interpretation of pollination syndromes (or the lack thereof) in their focal species.

\section{Conclusion}

Overall, we do not find support for the pollination syndrome concept in Oenothera; i.e. fewer than 50\% of species' primary pollinators were predicted by the traditional pollination syndromes of Faegri and van der Pijl (1979) and Oenothera did not cluster in morphospace using our quantitative floral trait measurements. While we do not find that floral traits predict current pollinators using either categorical or quantitative data, and there is no difference in adherence to the traditional pollination syndromes based on breeding system or pollinator specialization, our results add to the pollination biology literature by testing the pollination syndrome concept in a monophyletic clade with a diversity of pollination systems and ecotypes. Given that (I) ancestral Oenothera were likely moth pollinated and (2) extant Oenothera species with moth pollination systems were predicted most accurately, our results suggest that evolutionary history is important to consider when evaluating the relationship between floral form and contemporary pollinators. While pollinators are important selective forces that influence the evolution of floral traits, there are also multiple factors that influence floral form, such as multiple 
primary pollinator groups, antagonistic interactions, and pleiotropic effects on other plant traits (Reynolds et al. 2009; Strauss \& Irwin 2004). As pollination syndromes may result from convergent evolution of floral form due to pollinator mediated selection, the pollination syndrome concept is useful for guiding hypothesis development on the eco-evolutionary effects of pollination system interactions. However, to determine the current pollination system for a species, direct observation and data collection are still necessary. Collectively, our results demonstrate that in certain taxa, such as Oenothera, the pollination syndrome concept may not accurately predict contemporary associations between floral species and their primary pollinators.

\section{ACKNOWLEDGEMENTS}

Thank you to Dr. Peter Hoch, Dr. Peter Raven, Dr. Katherine Waselkov, Dr. Nicole Miller-Struttman, and Dr. Aimee Dunlap's lab for comments and discussion throughout the writing of the manuscript. We also thank two anonymous reviewers for their insightful comments which improved this manuscript's quality. We thank the following agencies for funding this work: National Science Foundation (DDIG 0910202), the Howard Hughes Foundation, American Women in Science, Botanical Society of America, Washington University in St. Louis, Sigma Xi, Prairie Biotic Research Inc., Missouri Native Plant Society, Webster Groves Nature Society, and the Missouri Botanical Garden.

\section{REFERENCES}

Abrahamczyk S, Lozada-Gobilard S, Ackermann M, Fischer E, Krieger V, Redling A, Weigend M (2017) A question of data quality - Testing pollination syndromes in Balsaminaceae. PLoS ONE I2:I-I5.

Anderson B, Terblanche JS, Ellis AG (2010) Predictable patterns of trait mismatches between interacting plants and insects. BMC Evolutionary Biology 10:204.

Armbruster WS, Gong YB, Huang SQ (201I) Are pollination "syndromes" predictive? Asian Dalechampia fit neotropical models. American Naturalist I78:135-I43.

Ashman T-L, Majetic CJ (2006) Genetic constraints on floral evolution: a review and evaluation of patterns. Heredity 96:343352.

Ashworth L, Aguilar R, Martén-Rodríguez S, Lopezaraiza-Mikel M, Avila-Sakar G, Rosas-Guerrero V, Quesada M (2015) Pollination syndromes: a global pattern of convergent evolution driven by the most effective pollinator. In: Pontarotti P (ed) Evolutionary biology: biodiversification from genotype to phenotype. Springer International Publishing, Switzerland, pp 203-224.

Austin MW, Horack P, Dunlap AS (2019) Choice in a floral marketplace: the role of complexity in bumble bee decision-making. Behavioral Ecology 30:500-508.

Baker HG (1955) Self-compatibility and establishment after "long distance" dispersal. Evolution 9:347-349.

Barrett SCH (2002) The evolution of plant sexual diversity. Nature Reviews Genetics 3:274-284.

Burkle LA, Alarcón R (20II) The future of plant-pollinator diversity: Understanding interaction networks across time, space, and global change. American Journal of Botany 98:528-538.

Burkle LA, Marlin JC, Knight TM. (2013) Plant-pollinator interactions over I20 years: loss of species, co-occurrence, and function. Science 339:I6II-I6I5.
Chartier M, Jabbour F, Gerber S, Mitteroecker P, Sauquet H, von Balthazar M, Staedler Y, Crane PR, Schönenberger J (20I4) The floral morphospace - a modern comparative approach to study angiosperm evolution. New Phytologist 204:84I-853.

Chittka L, Thomson JD, Waser NM (I999) Flower constancy, insect psychology, and plant evolution. Naturwissenschaften 86:36I-377.

Clarke KR (1993) Non-parametric multivariate analyses of changes in community structure. Australian Journal of Ecology I8:117I43.

Clinebell RR, Crowe A, Gregory DP, Hoch PC (2004) Pollination ecology of Gaura and Calylophus (Onagraceae, tribe Onagreae) in western Texas, U.S.A. Annals of the Missouri Botanical Garden 9I:369-400.

Danieli-Silva A, de Souza JMT, Donatti AJ, Campos RP, VicenteSilva J, Freitas L, Varassin IG (20I2) Do pollination syndromes cause modularity and predict interactions in a pollination network in tropical high-altitude grasslands? Oikos I2I:35-43.

Darwin CR (I862) On the various contrivances by which British and foreign orchids are fertilised by insects, and on the good effects of intercrossing. John Murray, London.

Davila YC, Wardle GM (2008) Variation in native pollinators in the absence of honeybees: implications for reproductive success of an Australian generalist-pollinated herb Trachymene incisa (Apiaceae). Botanical Journal of the Linnean Society 156:479-490.

Delpino F (1874) Ulteriori osservazioni e considerazioni sulla dicogamia nel regno vegetale. Atti della Societa Italiana Scientia Naturale 16:15I-349.

Dietrich W, Wagner WL, Raven PH (1997) Systematics of Oenothera section Oenothera subsection Oenothera (Onagraceae). Systemic Botany Monographs 50:I-234.

Dunlap AS, Papaj DR, Dornhaus A (2017) Sampling and tracking a changing environment: persistence and reward in the foraging decisions of bumblebees. Interface Focus 7:20160149.

Evans MEK, Hearn DJ, Hahn WJ, Spangle JM, Venable DL (2005) Climate and life-history evolution in evening primroses (Oenothera, Onagraceae): a phylogenetic comparative analysis. Evolution 59:1914-1927.

Faegri K, van der Pijl L (1979) The principles of pollination ecology. Pergamon Press, Oxford.

Fenster CB, Armbruster WS, Wilson P, Dudash MR, Thomson JD (2004) Pollination syndromes and floral specialization. Annual Review of Ecology, Evolution, and Systematics 35:375-403.

Fenster CB, Reynolds RJ, Williams CW, Makowsky R, Dudash MR (2015) Quantifying hummingbird preference for floral trait combinations: the role of selection on trait interactions in the evolution of pollination syndromes. Evolution 69:1 I I3-I 127.

Fishbein M, Venable L (1996) Diversity and temporal change in the effective pollinators of Asclepias tuberosa. Ecology 77:I06I-I073.

Gong W-C, Chen G, Vereecken NJ, Dunn BL, Ma YP, Sun WB (2015) Floral scent composition predicts bee pollination system in five butterfly bush (Buddleja, Scrophulariaceae) species. Plant Biology 17:245-255.

Guzmán B, Gómez JM, Vargas P (2017) Is floral morphology a good predictor of floral visitors to Antirrhineae (snapdragons and relatives)? Plant Biology 19:515-524.

Hildesheim LS, Opedal ØH, Armbruster WS, Pélabon C (2019) Fitness costs of delayed pollination in a mixed-mating plant. Annals of Botany I24:869-88I.

JMP (2009) JMP. SAS Institute Inc.

Johnson KA (2013) Are there pollination syndromes in the Australian epacrids (Ericaceae: Styphelioideae)? A novel statistical 
method to identify key floral traits per syndrome. Annals of Botany II2:I4I-I49.

Johnson SD, Steiner KE (2000) Generalization verses specialization in plant pollination systems. Trends in Ecology and Evolution I5:I40-I43

Johnson SD, Wester P (2017) Stefan Vogel's analysis of floral syndromes in the South African flora: An appraisal based on 60 years of pollination studies. Flora 232:200-206.

Kalisz S, Vogler DW (2003) Benefits of autonomous selfing under unpredictable pollinator environments. Ecology 84:2928-2942.

King C, Ballantyne G, Willmer PG (2013) Why flower visitation is a poor proxy for pollination: measuring single-visit pollen deposition, with implications for pollination networks and conservation. Methods in Ecology and Evolution 4:8I I-8I8.

Kingston AB, McQuillan PB (2000) Are pollination syndromes useful predictors of floral visitors in Tasmania? Austral Ecology 25:600-609.

Knauer AC, Schiestl FP (2017) The effect of pollinators and herbivores on selection for floral signals: a case study in Brassica rapa. Evolutionary Ecology 31:285-304.

Knuth P (1898) Handbuch der Blütenbiologie, unter Zugrundelegung von Herman Müllers Werk: "Die Befruchtung der Blumen durch Insekten." Engelmann, Leipzig.

Krakos KN (20II) The evolution and reproductive ecology of Oenothera (Onagraceae). PhD, Washington University, St. Louis, MO.

Krakos KN, Fabricant SA (2014) Generalized versus specialized pollination systems in Oenothera (Onagraceae). Journal of Pollination Ecology I4:235-243.

Krakos KN, Johnson MG, Hoch P, Wagner WL, Huang P, Raven $\mathrm{PH}$ (accepted) Molecular phylogenetics and origins of selfcompatibility in Oenothera (Onagraceae).

Krakos KN, Reece JS, Raven PH (20I4) Molecular phylogenetics and reproductive biology of Oenothera section Kneiffia (Onagraceae). Systematic Botany 39:523-532.

Lagomarsino LP, Forrestel EJ, Muchhala N, Davis CC (2017) Repeated evolution of vertebrate pollination syndromes in a recently diverged Andean plant clade. Evolution 7I:1970-1985.

Lázaro A, Hegland SJ, Totland Ø (2008) The relationships between floral traits and specificity of pollination systems in three Scandinavian plant communities. Oecologia 157:249-257.

Lehtilä K, Strauss SY (1999) Effects of foliar herbivory on male and female reproductive traits of wild radish, Raphanus raphanistrum. Ecology 80:116-I24.

Levin RA, Wagner WL, Hoch PC, Hahn WJ, Rodriguez A, Baum DA, Katinas L, Zimmer EA, Sytsma KJ (2004) Paraphyly in tribe Onagreae: insights into phylogenetic relationships of Onagraceae based on nuclear and chloroplast sequence data. Systematic Botany 29:147-164.

Li JK, Huang S-Q (2009) Effective pollinators of Asian sacred lotus (Nelumbo nucifera): contemporary pollinators may not reflect the historical pollination syndrome. Annals of Botany I04:845-85I.

Liu CQ, Huang S-Q (2013) Floral divergence, pollinator partitioning and the spatiotemporal pattern of plant-pollinator interactions in three sympatric Adenophora species. Oecologia, I73(4), I4II-I423.

Martén-Rodríguez S, Almarales-Castro A, Fenster, CB (2009) Evaluation of pollination syndromes in Antillean Gesneriaceae: evidence for bat, hummingbird and generalized flowers. Journal of Ecology 97:348-359.

Maruyama PK, Oliveira GM, Ferreira C, Dalsgaard B, Oliveira PE (2013) Pollination syndromes ignored: importance of non- ornithophilous flowers to Neotropical savanna hummingbirds. Naturwissenschaften 100:106I-I068.

Mayfield MM, Waser NM, Price MV (200I) Exploring the 'most effective pollinator principle' with complex flowers: Bumblebees and Ipomopsis aggregata. Annals of Botany 88:59I-596.

McCune B, Grace J (2002) Analysis of ecological communities. Gleneden Beach, OR: MJM Software.

McCune B, Mefford MJ (2006) PC-ORD: multivariate analysis of ecological data. MJM Software.

Mitchell RJ, Irwin RE, Flanagan RJ, Karron JD (2009) Ecology and evolution of plant-pollinator interactions. Annals of Botany 103:1355-1363

Moody-Weis JM, Heywood JS (200I) Pollination limitation to reproductive success in the Missouri evening primrose, Oenothera macrocarpa (Onagraceae). American Journal of Botany 88:1615I622.

Moreira-Hernández J, Muchhala N (2019) Importance of pollinator-mediated interspecific pollen transfer for angiosperm evolution. Annual Review of Ecology, Evolution, and Systematics 50:8.I-8.27.

Muchhala N (2006) The pollination biology of Burmeistera (Campanulaceae): specialization and syndromes. American Journal of Botany 93:108I-1089.

Munz PA (1938) Studies in Onagraceae XI. A revision of the genus Gaura. Bulletin of the Torrey Botanical Club 65:105-I22.

Murúa, M, Espíndola A (2015) Pollination syndromes in a specialised plant-pollinator interaction: does floral morphology predict pollinators in Calceolaria? Plant Biology 17:55I-557.

Nonnenmacher, HF (1999) The comparative floral ecology of vernal and autumnal Onagraceae in and near Konza Prairie Research Natural Area, Kansas. Doctoral Dissertation, St. Louis University.

Ollerton J, Alarcón R, Waser NM, Price MV, Watts S, Cranmer L, Hingston A, Peter CI, Rotenberry J (2009) A global test of the pollination syndrome hypothesis. Annals of Botany I03:I47II480.

Opedal $\varnothing \mathrm{H}$, Albertsen E, Armbruster WS, Pérez-Barrales R, Falahati-Anbaran M, Pélabon C (2016) Evolutionary consequences of ecological factors: pollinator reliability predicts mating-system traits of a perennial plant. Ecology Letters I9:I486I495.

Prieto-Benítez S, Dötterl S, Giménez-Benavides L (2015) Diel variation in flower scent reveals poor consistency of diurnal and nocturnal pollination syndromes in Sileneae. Journal of Chemical Ecology 4I:I095-II04.

Quintero E, Genzoni E, Mann N, Nuttman C, Anderson B (2017) Sunbird surprise: a test of the predictive power of the syndrome concept. Flora 232:22-29.

Raven PH (1979) A survey of reproductive biology in Onagraceae. New Zealand Journal of Botany 17:575-593.

Raven PH (1988) Onagraceae as a model of plant evolution. In: Gottlieb LD, Jain SK (eds) Plant evolutionary biology. Springer, Dordrecht, pp 85-107.

Raven PH, Gregory DP (1972) A revision of the genus Gaura (Onagraceae). Memoirs of the Torrey Botanical Club 23:I-96.

Reynolds RJ, Westbrook MJ, Rohde AS, Cridland JM, Fenster CB, Dudash MR (2009) Pollinator specialization and pollination syndromes of three related North American Silene. Ecology 90:2077-2087.

Rodrigues DM, Caballero-Villalobos L, Turchetto C, Jacques RA, Kuhlemeier C, Freitas LB (2018) Do we truly understand pollination syndromes in Petunia as much as we suppose? AoB Plants IO:I-I5. 
Rosas-Guerrero V, Aguilar R, Martén-Rodríguez S, Ashworth L, Lopezaraiza-Mikel M, Bastida JM, Quesada M (20I4) A quantitative review of pollination syndromes: do floral traits predict effective pollinators? Ecology Letters 17:388-400.

Schiestl FP, Johnson SD (2013) Pollinator-mediated evolution of floral signals. Trends in Ecology and Evolution 28:307-3I5.

Smith SD (2010) Using phylogenetics to detect pollinator-mediated floral evolution. New Phytologist I88:354-363.

Smith SDW, Ané C, Baum DA (2008) The role of pollinator shifts in the floral diversification of Iochroma (Solanaceae). Evolution 62:793-806.

Stebbins GL (1970) Adaptive radiation of reproductive characteristics in angiosperms, I: Pollination mechanisms. Annual Review of Ecology and Systematics I:307-326.

Straley GB (1977) Systematics of Oenothera sect. Kneiffia (Onagraceae). Annals of the Missouri Botanical Garden 64:38I424 .

Strauss SY, Irwin RE (2004) Ecological and evolutionary consequences of multispecies plant-animal interactions. Annual Review of Ecology Evolution and Systematics 35:435-466.

Tripp EA, Manos PS (2008) Is floral specialization an evolutionary dead-end? Pollination system transitions in Ruellia (Acanthaceae). Evolution 62:1712-I737.

Valdivia CE, Niemeyer HM (2006) Do floral syndromes predict specialisation in plant pollination systems? Assessment of diurnal and nocturnal pollination of Escallonia myrtoidea. New Zealand Journal of Botany 44:135-I4I. van der Niet T, Johnson SD (2012) Phylogenetic evidence for pollinator-driven diversification of angiosperms. Trends in Ecology and Evolution 27:353-36I.

Vogel S (1954) Blütenbiologische typen als elemente der sippengliederung. Fischer, Jena.

Wagner WL, Hoch PC, Raven PH (2007) Revised classification of the Onagraceae. Systematic Botany Monographs 83:I-240.

Wagner WL, Krakos KN, Hoch PC (2013) Taxonomic changes in Oenothera sections Gaura and Calylophus (Onagraceae). PhytoKeys 28:6I-72.

Waser NM, Chittka L, Price MV, Williams NM, Ollerton J (1996) Generalization in pollination systems, and why it matters. Ecology 77:1043-1060

Waser NM, Ollerton J (2006) Plant-pollinator interactions: from specialization to generalization. Chicago Press, Chicago.

Whittall JB, Hodges SA (2007) Pollinator shifts drive increasingly long nectar spurs in columbine flowers. Nature 447:706-709.

Wilson P, Castellanos MC, Hogue JN, Thomson JD, Armbruster WS (2004) A multivariate search for pollination syndromes among penstemons. Oikos I04:345-36I.

Wolfe LM, Sowell DR (2006) Do pollination syndromes partition the pollinator community? A test using four sympatric morning glory species. International Journal of Plant Sciences I67:1169II 75 .

Yang C, Guo Y (2005) Floral evolution: beyond traditional viewpoint of pollinator mediated floral design. Chinese Science Bulletin 50:24I3-24I7. 